EPiC Series in Language and Linguistics
Volume 2, 2017, Pages 214-223
Professional and Academic Discourse:
an Interdisciplinary Perspective

\title{
"I Know How You Feel": Multifaceted Insights into the Expression of Support Strategies in Computer-Mediated-Communication
}

\author{
Carmen Maíz-Arévalo* and Alfonso Sánchez-Moya ${ }^{\dagger}$ \\ Universidad Complutense de Madrid, Spain \\ cmaizare@ucm.es, asmoya@ucm.es
}

\begin{abstract}
This study seeks to explore the wide range of strategies that online users employ to express their linguistic support in computer-mediated-communication environments. Based on a purely semantic definition of the term support, this research puts forward a taxonomy containing several strategies by means of which support can be discursively transmitted in digital contexts. This taxonomy is thus applied to data collected from two prototypical communicative practices taking place online: a Facebook group and an Intimate Partner Violence (IPV) forum, which amounts to a total of 12,327 and 26,452 words respectively. Findings show the most salient realisations for expressing support in these two online settings, drawing on the implications the use of a particular sort of strategy may have with regard to the communicative practices under investigation.
\end{abstract}

\section{Introduction}

In situations of face loss, the affected interactant can try to repair their lost face by means of corrective facework strategies like humour, aggression, remediation, etc. (Hodgins et al. 1996; Jeon and Mauney 2001, among others). However, the other interlocutors in the exchange can also feel inclined to repair their partner's face loss. One of the most commonly employed strategies is to express support for the person whose face has been damaged in front of their peers. Technological advances and the advent of Web 2.0 have allowed for the expression of support strategies to extend to computer-mediated communication. Thus, support can be provided through social media like blogs, forums, Facebook groups, online support groups, etc. For instance, Winzelberg et al. (2003) analysed the positive effects on cancer patients of an asynchronous social support group. Coulson et al. (2007) studied the effects of online support on patients affected by Huntington's disease, whilst Hwang et al. (2010) focused upon a weight-loss community. In a more recent study, Angouri and Sanderson (2016) analysed the postings

* Senior Lecturer, Department of English Language and Linguistics, Complutense University of Madrid

${ }^{\dagger}$ Predoctoral researcher, Department of English Language and Linguistics, Complutense University of Madrid 
of a Rheumatoid Arthritis forum. The present paper aims to analyse ordinary exchanges both in English and in Spanish. More specifically, Spanish strategies of support will be studied in a Facebook common interest group, whose only purpose is to entertain themselves whilst sharing their mutual love for a Spanish popular singer. This study intends to check whether gender plays any role in the expression of support since prior research has shown that female speakers are, on the whole, more supportive than their male counterparts, especially with regard to the expression of emotional support (Cupach and Metts 1986; Hamilton \& Hagiwara 1992; Hodgins et al. 1996; among others). Similarly, English strategies of digital support will be explored in an online public forum used by women who have experienced (or still are experiencing) intimate partner violence (IPV). Although gender itself is understood here as a central part of IPV, we seek to establish connections between the different use of support strategies and the different stages that commonly characterise an abusive relationship of this sort. The rest of the paper is structured into five sections. Section 2 defines support and describes a pragma-discursive taxonomy of the strategies employed to express it. Section 3 focuses on the methodology; more specifically, it describes data compilation and the dataset at hand. The fourth section presents the analysis of the data before concluding in section five.

\section{Towards a Taxonomy of Support Strategies}

According to its first entry in the MacMillan dictionary, "to support" is defined as:

1a. to approve of an idea or of a person or organization (my emphasis), which in turn is defined as: having a favourable view of something / Speaking or thinking favourably of / Consenting or agreeing.

1b. to help someone and be kind to them when they are having a difficult time

1c. to hold the weight of someone or of something such as a building or structure so that they do not move or fall.

Taking this definition, previous research and the data at hand into consideration, it is hence possible to establish the following system of "expressing support":

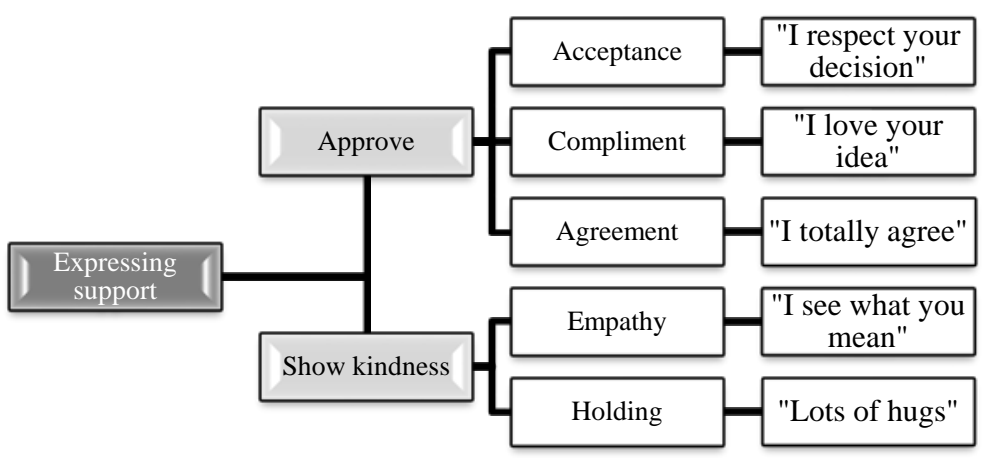

Figure 1: Towards a taxonomy of support strategies

Support is therefore to be expected especially in moments where a user is having a difficult time, up to the extent that they want to abandon the group. The threat of disruption is likely to trigger an immediate response by other members for whom keeping the group glued together becomes of paramount importance, since group unity below their common interest is the raison d'être of the group itself. It could thus be argued that, rather than supporting another member out of solidarity, they are 
resorting to these strategies with the ultimate selfish aim to avoid the group from weakening and eventually disappearing (Herring 2004). As illustrated by Figure 1, support can be expressed by means of different sub-strategies, as follows:

\section{(i) Approve: acceptance}

Speakers can express their support of an interlocutor by accepting their opinions (not necessarily agreeing with them or thinking highly of them). This is illustrated by the examples below. Note that examples coming from the Spanish corpus are listed using the abbreviation (SP), whereas (EN) is used to illustrate those from the English corpus.

(SP_1) pero en fin tus decisiones tendrás [but, well, you'll have your decisions]

(EN_1) This really is a big step in the right direction

(ii) Approve: compliment

Complimenting the addressee can be used to express approval of her actions or her person rather than simply accepting both, by positively evaluating them, as illustrated by (SP_2) and (EN_2) below:

(SP_2) participas muchísimo en el grupo y eso a mí me gusta [you really participate a lot in the group and I like that indeed]

(EN_2) you rock, your son knows this, and somewhere deep within, so do you

(iii) Approve: agreement

Agreeing with the user's ideas or decisions is a clear way to support them. Although closely related to approve: acceptance, agreement implies a positioning next to the user rather than simply accepting their decision -with which one might disagree. Agreement is typically expressed by formulaic linguistic realizations, as in (SP_3) and (EN_3):

(SP_3) Si [sic] estoy totalmente de acuerdo contigo [Yes, I totally agree with you]

(EN_3) i think that too

\section{(iv) Show kindness: empathy}

Showing empathy implies for the addressee to put themselves in the user's shoes, sharing their feelings of sadness and dissatisfaction. Typical linguistic realizations include the formula: "te entiendo" (I understand you) or "I know how you feel", as illustrated by (SP_4) and (EN_4):

(SP_4) un saludo animo [sic] te entiendo [Cheers, cheer up, I understand you]

(EN_4) I can relate hun.. i really really can

\section{(v) Show kindness: hold}

One of the metaphorical uses of "support" is "to hold the weight of something so that it will not fall". In terms of interactants, this might be understood as "emotionally hugging" the user who is going through a hard situation. Given the disembodied nature of the channel, these hugs have to be explicitly verbalised, as in the following examples:

(SP_5) Un abrazo! [a hug]

(EN_5) Huge hugs of strength are coming to you from me

\section{Methodology}

The dataset under scrutiny was compiled following a netnographic approach, defined as "a participant-observational research based in online fieldwork [that] uses computer-mediated 
communications as a source of data to arrive at the ethnographic understanding and representation of a cultural or communal phenomenon" (Kozinets 2010: 60).

For the Spanish dataset, a participant observer who has been part of the community for almost a year (even if not acting as a pro-active member) gathered the data belonging to the period from January to February 2015. The period was randomly chosen so as to ensure completely authentic data was collected and no bias was at work -i.e. looking for the phenomenon at hand. The resulting corpus involves 12,327 words and 412 conversational turns in Spanish.

The English corpus however consists of data collected from an online public forum in which female users that are at different stages of abusive relationships can anonymously engage in support practices. It should be noted that this forum is divided into different subcategories which seek to correlate different stages within an IPV relationship (Is it domestic abuse?, Leaving an abusive relationship and Life after abuse, inter alia). The total corpus considered for this study amounts to 26,452 words, which were obtained from fifteen randomly-selected forum threads posted in March 2015 and of similar size (five threads for each of the forum subcategories mentioned above).

Both corpora were then manually coded in the light of the proposed taxonomy for support strategies included above. Results deriving from this process are discussed in the next section.

\section{Data analysis}

\subsection{Digital Support Strategies: Facebook}

As already mentioned, this study concentrates on two cases where very active group members show their discomfort with the group and express their desire to abandon it, provoking its disruption. Case 1 takes place on 31st January when a very active member (Ana) gets criticised for publishing an interview where she disclosed private information about the singer. This triggers a divide in the group between those who support her contribution and those who favour sticking strictly to the singer's music, without revealing personal information about his life. Ana, the user whose face is at risk, expresses her discontent in the following post, where she threatens to give the group up:

(SP_6) Todo se puede decir con educación y respeto, defendiendo lo que uno piensa sin atacar lo que piensa el otro. ¡iQué incomoda me siento aquí ya!!... no duraré mucho . Saludos [Everything can be said with politeness and respect, defending one's opinión without attacking others'. How uncomfortable I feel here!! ... I won't stay long. Greetings]

In case 2, Lily, another one of the group's most active members, leaves the group just a couple of days later (2nd Feb). Although without specifying the reason why she is leaving, she does so in the following emotional farewell:

(SP_7) Chic@s ha sido un placer pertenecer a este grupo.Os llevaré en el corazón.

Muchas gracias por todo, a todo el mundo. Seguiré a mi [Cantante], pero desde la sonbra [sic].

Mil besosss. [Guys it's been a pleasure to belong to this group. I'll carry you in my heart. Thanks a lot for everything, everyone. I'll follow my [Singer's name] but from the shadows. A thousand kisses]

Both cases illustrate the same situation insofar as group disruption is at stake, which might explain why the other users actively resort to repairing the leaving member's face loss so as to keep the group's unity. However, there is also a major difference between both exchanges since, in case 1, most users are aware of the reason why Ana is leaving and her decision to do so has opened a core debate as to what is "publishable" material or not. In case 2, Lily's reasons to abandon the group are unknown and seem due to a personal, emotional decision. This might explain why, in the first scenario, there are fewer users who post more actively and generate inner discussion while case 2 provokes more users expressing 
their surprise but fewer of them posting more than once. Thus, case 1 triggers 37 posts by 7 male users (who produce 15 posts) and 9 female users (who produce 22 posts). In case 2, group abandonment generates 33 posts by 17 female users (who produce 19 posts) and 9 male users (who produce 14 posts). The support strategies employed in each case will be analysed in more detail in the coming subsections; the hypothesis being that each context will lead to different support strategies.

In case 1, approve: acceptance is hardly employed (2 occasions, 5.5\% of the cases) and, when doing so, it is not directly addressed to the member whose face is being repaired but to others, in an attempt by the members to preserve their own face as respectful members. In other words, since Ana has deleted her initial post -the one that caused all the disruption -these members accept her decision to do so, as illustrated by the following exchange:

(SP_8) Subimos la entrevista y la ponemos aquí, Ana decidió quitarla pero yo la pongo se donde esta [sic]

LL: Si Ana no quiere... yo la respeto

BD: pero si no quiere está en su derecho, y por supuesto hay que respetarla [We upload the interview and put it here, Ana decided to delete it but I will restore it, I know where it is // But if

Ana doesn’t want to... I respect her // But if she doesn’t want to, she has all the right to do so, and of course we have to respect her]

In case 2, approve: acceptance is the second support strategy, used in five cases (15\%). In both cases, it is interesting to see that it is only female users who employ this strategy, with no examples by the male members of the group. One plausible reason might be that female users feel more identified with the member whose face has been damaged (also female) and accept their decisions, appearing as more tolerant than their male counterparts.

With regard to approve: compliment, this is the most common strategy in case 1 , where it is employed on five occasions (amounting to 13.5\% of the cases), although 3 of them are used by the same member in the same post and one later on (curiously enough, this is Lily, who will abandon the group in case 2 just a few days later), as can be seen in (SP_9) and (SP_10):

(SP_9) Me encanta tu entrevista Ana. Has estado a la altura. Fantástica. [I love your interview,

Ana. You've been up to expectations. Fantastic]

(SP_10) No sé, pero has estado fantástica [I don't know, but you've been fantastic]

In case 2 , it is also employed in $15.2 \%$ of the cases. In terms of gender, 5 out of the 6 compliments are paid by other female users. The only case of a compliment paid by a male user is (SP_11), which is conventionally implicit:

(SP_11) Un placer, Lily [A pleasure, Lily]

The general trend, thus, is for compliments to be paid mostly by female users rather than their male counterparts, which seems to follow the general pattern of compliments (Holmes 1988; Maíz-Arévalo 2010).

In case 1, there are only three tokens of the strategy approve: agreement (8\% of the cases), where users express their agreement with Ana that freedom of expression and tolerance should be a must in the group:

(SP_12) Subrayo tus palabras menos las de irte de la pagina [sic] [I subcribe your words except for leaving the group]

In case 2, there are no examples of approve: agreement, most likely because users ignore the reason that has triggered their peer's discontent and hence the only thing to do is accepting her decision. In such a context, expressing agreement with her leaving might be counterproductive and trigger the opposite effect; that is, rather than expressing support, it might be inferred by the affected user as an 
invitation for her to abandon the group. In fact, this is what happens in the following example, which becomes highly aggressive:

(SP_13) quien no quiera estar, pues ya sabe donde [sic] esta [sic] la puerta [if someone does not want to be here, they already know where the door is]

In terms of gender, the scarcity of the sample does not allow to find any general trends, although two out of the three cases are produced by female users, more participative in general terms.

With regard to the strategy show kindness: empathy, it is rarely used in case 1 ( $5.5 \%$ of the cases), where no gender differences are observed whilst there are no cases of this strategy in Case 2. A possible reason might be that the user's personal decision to abandon the group is unknown to most users. Hence, her decision is simply respected as already mentioned.

When it comes to the strategy show kindness: holding, and as already pointed out, one of the metaphorical uses of "support" is "to hold the weight of something so that it will not fall". In terms of conversational exchanges, this might be understood as "emotionally hugging" the user who is going through a hard situation. Given the disembodied nature of the channel at hand, these hugs have to be explicitly verbalised, as in the following example from case 2:

(SP_14) Un abrazo gordote Lily!!! [A huge hug, Lily!!!]

In (SP_14), the use of the suffix -ote, a Spanish colloquial augmentative, adds a more informal and tender tone to the whole message, which is brief (this is its only content) but effectively shows support to the addressee, whose decision to leave the group is implicitly respected by giving her a kind and warm farewell. The expression of show kindness: hold takes the form not of a metaphorical hug but of a circle of friends, supporting and loving the affected user as illustrated by (SP_15):

(SP_15) Somos tus amigos, estamos contigo [We are your friends, we are with you]

Even though there are only two tokens in each case (5.5\% and 6\%, respectively), it is remarkable that all of them are exclusively produced by female users, reinforcing the stale stereotype that female speakers are more emotional than their male counterparts.

\subsection{Digital Support Strategies: the IPV Online Forum}

As previously pointed out, this study aims at exploring the array of support strategies used by female users of an online forum who are (or were) having experiences with IPV. Unlike the motivations that drove the previous study, the main objective of exploring strategies to express digital support in this forum is to establish a possible correlation between the different sorts of mechanisms used by these users and the corresponding forum subcategory in which these strategies were found. For this reason, forum threads from three different forum communities were collected and analysed: Is it domestic abuse?, Leaving an abusive relationship and Life after abuse. Needless to say, these three forum communities were thought to represent three stages within an abusive relationship: a) an initial stage, in which the abused woman is still trying to figure out if she is suffering from abuse; b) an intermediate stage, in which the victim is aware of her state and finds the many possible ways to cope with the abusive relation she is in and c) a final stage in which women find themselves out of the abusive relationship and openly admit (and digitally share) being so.

Broadly speaking, the taxonomy for support strategies sketched in Figure 1 above worked nicely when applied to the English corpus. However, it is worth noting that some instances of data did not seem to fit in any of the proposed categories. In a nutshell, it was observed that one of the possible ways in which the users of this forum showed their support to other users in need was by means of urging them to do something, i.e., encouraging the thread poster to take action. There may be several reasons for this, but it can be argued that the main cause may lie in the different nature of the data analysed for 
both studies. Whereas the Spanish corpus consists of a Facebook community that supports a musician (and its activity is mostly online-based), the English corpus takes data from a forum that can be envisaged as a source of information or support from which users would also benefit in offline settings. This is why it was common to find directives and imperatives that, despite being originated in an online scenario, were to be taken to an offline context. Having considered this, it was then necessary to include an additional category to analyse the English corpus: urging. Prototypical realisations of this support strategy are examples (EN_6) and (EN_7)

(EN_6) Ring 101 they will advise you

(EN_7) Report it anyway, I say!

It was certainly problematic to include this urging in one of the two initial branches of the taxonomy, since it could be seen neither as approve nor as show kindness. Regardless of this theoretical decision yet to be made, urging was eventually included as part of the taxonomy, resulting in Figure 3 below.

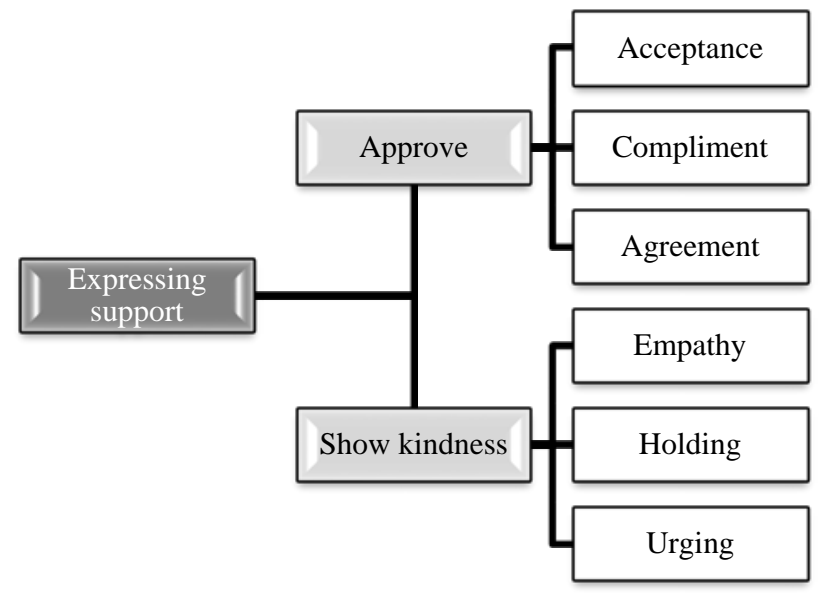

Figure 3: Urging as support strategy to be used in the analysis of forum data

Once the corpus was analysed, a total of 323 support occurrences were identified. The randomlyselected threads were manually coded twice, but there is still a possible deviation that should be accounted for. Similarly, this would benefit from peer-coding, which would perhaps lead to slight differences in the number of strategies according to the type to which they belonged. Notwithstanding this issue, the overall picture of support strategies pinned down in the English corpus is illustrated in Table 1 below. 


\begin{tabular}{lrrr|r}
\hline $\begin{array}{l}\text { Support strategy } \\
\text { (IPV online forum) }\end{array}$ & $\begin{array}{r}\text { Is it } \\
\text { DAB? }\end{array}$ & $\begin{array}{r}\text { Leaving } \\
\text { DAB }\end{array}$ & $\begin{array}{r}\text { Life after } \\
\text { DAB }\end{array}$ & TOTAL \\
\hline Approve: acceptance & 20 & 12 & 3 & 35 \\
Approve: compliment & 7 & 16 & 5 & 28 \\
Approve: agree & 10 & 11 & 27 & 48 \\
Show kindness: empathy & 14 & 18 & 9 & 41 \\
Show kindness: holding & 34 & 59 & 23 & 116 \\
Urging & 24 & 21 & 10 & 55 \\
\hline TOTAL & 109 & 137 & 77 & 323 \\
\hline
\end{tabular}

Table 1: Support strategies in IPV online forum

This table has two major readings. The first one is related to the ways in which every type of support strategy is used across the three different forum subcategories. As can be inferred from the table, support strategies that rely on showing kindness are more salient in the corpus under scrutiny. In fact, 157 strategies can be categorised under the show kindness strategy, among which 116 correspond to holding and 41 to empathy. Conversely, a slightly inferior figure stands for all the approve strategies (111). Although the difference among them cannot be said to be very drastic, this deviance may suggest a more remarkable inclination by female users of this forum not to rely upon approval to convey their digital support. Rather, they opt for a more empathetic sort of support manifestation which is mostly realised by means of discursive holding. The fact that this strategy is the one which peer users incline to employ may have implications for dealing with women survivors from a health-care professional perspective. In a similar vein, instances of show kindness: empathy were consistently found in the three subcategories and were again mostly found in the second subcategory (Leaving an abusive relationship).

Urging is the second most used strategy to express support in the English corpus. As noted elsewhere, the nature of the data analysed does justify the prominence of this strategy, since users of this forum recur to this online setting to seek support there but, in many cases, it is to be transferred to offline settings. This explains why urging strategies are more salient in the first subcategory, where users are generally confused and not knowing how to proceed. It comes as no surprise to observe that the use of this particular strategy is minimised in the last subcategory, where users seem to be less dependent on support mechanisms.

It is remarkable to notice that approve: compliment is the least frequent support strategy traced in this corpus. This is particularly interesting if the Facebook counterpart of this study is recalled where it is precisely compliments the support strategy that outnumbered the others, especially if the female participants are taken into account. Although cultural differences (Spanish versus British) would surely apply in this case (Maíz-Arévalo 2010), it is still curious that female Facebook users opted for complimenting when trying to show support online in a disruptive situation. The very limited use of compliments (if compared to the rest) in the English corpus may highlight again the importance of considering the nature of the data being contrasted. It is no coincidence that female users of the IPV forum, who are generally believed to suffer from low self-esteem and related psychological issues (Campbell 2004), are less keen on using strategies such as compliments (which may be thought of a more positive-reinforcement mechanism). Despite its scarcity, note that the strategy approve: compliment is mostly used in the second subcategory (Leaving an abusive relationship), the stage in which they are more likely to benefit from this reinforcement we mentioned before.

It is worth commenting on the behaviour of two of the strategies whose frequency is somewhat in sharp contrast if its use is compared in the three subcategories: acceptance and (dis)agreeing. On the one hand, it seems that strategies that rely on acceptance by the other forum users tend to dissolve from 
the first subcategory to the third one. On the other hand, quite on the contrary, (dis)agreeing strategies are less common in the first subcategory but certainly more obvious in the third one. As suggested in Section 2 above, acceptance does not necessarily require agreeing whereas the latter does imply a closer positioning to the user. Therefore, this may suggest that forum users supporting other users writing in the Is it domestic abuse? community take a more detached stance to express their support by just accepting and acknowledging both the thoughts and feelings of those looking for advice, a tendency which fades in the other two subcategories. Interestingly, the opposite trend is observed when (dis)agreeing is considered. In fact, support strategies of this sort mostly occur in the third subcategory (Life after abuse). Thus, users expressing digital support in this subcategory may feel that less impersonal strategies are now more convenient. This triggers a more engaged nuance in their ways of showing support, which certainly require a closer positioning to the other users. This may also explain the reason why the total number of support strategies in this third subcategory is inferior if compared to the two others.

The second major reading that can be made from Table 1 above is related to the total number of support strategies found in each subcategory. Thus, according to the forum threads analysed for this study, it seems that a higher proportion of support strategies is found in the second forum subcategory (42.41\% of the total), which corresponds to a rather intermediate stage within the abusive relationship (Leaving an abusive relationship). Users who write in this subcategory generally acknowledge the fact they are being abused, thus trying to find support from those users that have presumably lived the same situation in the attempt to find possible solutions to it. It can be argued then that users sharing their experiences in this second subcategory (Leaving an abusive relationship) are those who make a greater use of support strategies, thus suggesting the greater need users in this subcategory may have when it comes to finding support among other forum users. This contrasts with the inferior amount of strategies found in the third subcategory (23.83\% of the total). This finding is at odds with our initial expectations, which hypothesised a more even proportion across the three subcategories. However, it was interesting to find out that it was complex to apply the taxonomy proposed there, and support strategies were therefore scarcer. Nonetheless, it could be argued that the most common realisation of support in this third subcategory (Life after abuse) was activated by means of personal narratives of success. Likewise, it is noteworthy to observe how the narrative perspective shifted, placing less emphasis on other forum users and putting more emphasis on themselves as survivors from whom the rest of users could find support.

\section{Concluding Remarks}

This research has first put forward a taxonomy to analyse support strategies in online environments and has then applied it to two particular settings: Facebook and online forums. Despite working nicely for both datasets in broad terms, some adjustments had to be made to account for the character of some of the data under investigation.

With regard to the Facebook dataset, results show that there is a wide variety of strategies to express support but their use is context-bound, with case 1 displaying all the strategies as opposed to case 2, where users resort to only two strategies. This difference might be due to the fact that, in case 1 , users know the cause of disruption and can therefore elaborate the way they express their support whereas in case 2, they ignore why their peer is leaving and hence tend to either accept or compliment her decision. Gender seems to play a crucial role in the expression of support, with female users displaying a wider range of support strategies and outnumbering some strategies which have been traditionally linked to female interlocutors such as complimenting other female users, agreeing with them and accepting their decisions. 
As for the forum counterpart (most likely influenced by the rather specific nature of the forum itself), the most salient support strategy used among users participating there was that of show kindness: holding. The fact that women who have experienced IPV experiences themselves are keen to use this particular strategy highlights the importance of approaching women experiencing IPV by expressing support which discursively relies upon holding mechanisms. Conversely, female users of this forum used compliments as a way of showing support to a lesser extent, which contrasts the pattern found among Facebook users investigated for this research.

Further research could mostly focus on overcoming the limitations of this study. Thus, it would be necessary to test the validity of the taxonomy proposed here with larger datasets and a wider variety of digital sources. Additionally, it would also be interesting to explore other repair strategies which at first sight may be affected by gender too (appealing to the group's unity, for instance). Similarly, research of this sort could focus on how purposefully "ungendered" identities express support and explore whether they still attach to certain pragmalinguistic behaviours associated with gender.

\section{References}

Angouri, J. \& Sanderson, T. (2016). 'You'll find lots of help here'unpacking the function of an online Rheumatoid Arthritis (RA) forum. Language and Communication 46, 1-13.

Campbell, J. C. (2004). Helping women understand their risk in situations of intimate partner violence. Journal of Interpersonal Violence, 19(12), 1464-1477.

Coulson, N. S., Buchanan, H., \& Aubeeluck, A. (2007). Social support in cyberspace: a content analysis of communication within a Huntington's disease online support group. Patient education and counseling, 68(2), 173-178.

Cupach, W. R. \& Metts, S. (1986). Accounts of relational dissolution: A comparison of marital and non-marital relationships. Communications Monographs, 53(4), 311-334.

Hamilton, V. \& Hagiwara, S. (1992). Roles, responsibility, and accounts across cultures. International Journal of Psychology 27(2), 157-179.

Herring, S. (2004). Slouching toward the ordinary: Current trends in computer-mediated communication. New media \& society, 6(1), 26-36.

Hodgins, H. S., Liebeskind, E., \& Schwartz, W. (1996). Getting out of hot water: Facework in social predicaments. Journal of Personality and Social Psychology, 71(2), 300-314.

Holmes, J. (1988). Paying compliments: A sex-preferential politeness strategy. Journal of Pragmatics 12, 445-465.

Hwang, K. O., Ottenbacher, A. J., Green, A. P., Cannon-Diehl, M. R., Richardson, O., Bernstam, E. V., \& Thomas, E. J. (2010). Social support in an Internet weight loss community. International journal of medical informatics, 79(1), 5-13.

Jeon, L. \& Mauney, S. (2001). “As Much As I Love You, I'll Never Get You to Understand”: Political Discourse and 'Face'Work on Facebook. Discourse, 67-75.

Kozinets, R. V. (2010). Netnography: Doing ethnographic research online. London: Sage.

Maíz-Arévalo, C. (2010). Intercultural pragmatics: A contrastive analysis of compliments in English and Spanish. En J. I. Marín Arrese, Discourse and communication: Cognitive and functional perspectives (págs. 175-208). Madrid: Dikynson.

Winzelberg, A. C. (2003). Evaluation of an internet support group for women with primary breast cancer. Cancer 97 (5), 1164-1173. 